\title{
A REFORMA EDUCACIONAL NA AMÉRICA LATINA NO CONTEXTO DE GLOBALIZAÇÃO
}

\author{
JUAN CASASSUS \\ Especialista Principal da Unesco/Oficina Regional \\ de Educação para a América Latina e Caribe \\ jcasassus@unesco.cl \\ Tradução: Luiz Pontual
}

\begin{abstract}
RESUMO
O artigo analisa as reformas educacionais ocorridas na América Latina, na década de 90, com o objetivo de dar indicações sobre como opera a regionalização no plano da cultura e das instituições e sobre os conteúdos desses processos macros, independentemente das variações nacionais e locais. Efetua também um balanço dos objetivos expressos por esses conteúdos após uma década de reformas educacionais na região. Embora o trabalho focalize o nível regional, a análise se apóia nas ações no nível nacional, uma vez que elas são estruturadas pelas politicas nacionais e, portanto, ocorrem dentro de um espaço definido por essas políticas, a Nação.

REFORMADOENSINO-AMÉRICALATINA - CICLODEREFORMASEDUCACIONAISNA AMÉRICALATINA-GLOBALIZAÇÃO
\end{abstract}

\begin{abstract}
THELATINAMER/CANEDUCATIONAL REFORMIN THECONTEXT OFGLOBALIZATION. The article analyzes educational reforms in Latin America in the 1990s to give indications of how regionalization operates on the cultural and institutional plane and of the contents of this macro process, independently of local and national variations. It also takes stock of the objectives expressed by content after a decade of educational reform in the region. Even though the article focuses on the regional level, the analysis is supported in national level activities, since they are structured by policies which define the arena of the nation.
\end{abstract}

Este texto é de completa responsabilidade do autor e de nenhuma maneira compromete a Unesco ou necessariamente representa a visão da Organização. $\bigcirc$ autor também agradece a Julia Cubillos por sua contribuição na recompilação de dados relativos ao financiamento da educação.

Agradecemos a colaboração de Miriam Bizzocchi na reordenação das tabelas e gráficos (N. da E.). 
Ainda que o campo multidisciplinar da globalização seja recente, os processos de globalização não o são. Em geral tende-se a reconhecer suas origens no descobrimento da América e no sistema global da Península Ibérica, estabelecidos há pouco mais de 500 anos. O que é recente é a ampliação das áreas que se vêem afetadas pela globalização e a velocidade com a qual está ocorrendo: assim, processos próprios do desenvolvimento da esfera econômica como a produção, as finanças e o comércio têm sido afetados.

Mas não é somente o campo da economia que está sendo atingido. Também estão ocorrendo processos em outras esferas, como no plano da identidade e da cultura. Uma forma de perceber o processo de globalização é considerá-lo do ponto de vista da desterritorialidade, no qual o Estado nacional perde suas fronteiras e emergem outros espaços para a configuração da identidade e da cultura.

Nesse sentido, muita atenção tem sido dada ao espaço da globalização, impulsionada pelo comércio mundial e tecnologias de informação. Em contrapartida, a ênfase tem sido colocada também no espaço local, dessa vez, igualmente impulsionada pelas tecnologias da informação e pelos processos de democratização. De fato, a perda da presença do Estado nacional tem sido acompanhada pela emergência da tensão que se dá entre o local, assegurado particularmente nos processos de descentralização, e o mundial.

Nesse quadro, tem-se dado pouca atenção ao exame de um terceiro processo de configuração de identidades: o nível regional. A configuração de blocos comerciais e culturais é claramente perceptível na Europa e na Ásia. Na América Latina, o Mercosul e a Coordenação Econômica da América Central são expressões desse processo. Nesse trabalho, o nível regional constitui a unidade de análise, por isso o foco está situado nesse terceiro processo. Devemos notar, entretanto, que as ações, na prática, não estão estruturadas no nível regional e sim pelas políticas nacionais e, portanto, ocorrem dentro de um espaço definido por essas políticas, a Nação. Por isso, neste trabalho, ainda que a análise se apóie nas ações no nível nacional, a interpretação das reformas educacionais se efetua no terceiro nível, o regional.

A análise é possível porque existe uma base empírica: as reformas ocorrem dentro de um marco histórico. Isso quer dizer que os processos ocorrem dentro de um espaço/tempo, em certos contextos, cujos conteúdos estão enquadrados em sistemas de idéias que estão presentes no nível regional e influem neles.

Esses sistemas de idéias operam em várias áreas. Hoje a área mais influente é a da economia. No entanto, é talvez no plano cultural, em particular o da educa- 
ção, que se possa apreciar mais claramente a permeabilidade em torno de um processo de regionalização.

Havendo situado o nível de análise, estabeleçamos que o propósito deste trabalho é dar indicações acerca de I) como opera a regionalização no plano da cultura e das instituições; 2) quais são os conteúdos destes processos macros, independentemente das variações que possam ocorrer no nível nacional e local e 3) um balanço depois de dez anos de reformas educacionais.

Considerar as reformas na América Latina numa perspectiva regional mostra um nível de realidade que não é um fenômeno novo. Para tanto, basta considerar que o atual ciclo é um segundo ciclo de reformas educacionais na América Latina. O primeiro ciclo se deu na década de 1960 e sua regionalidade manifestouse pela simultaneidade e características comuns. $\bigcirc$ primeiro ciclo, independentemente dos diferentes níveis de desenvolvimento, teve por característica comum a de ser um ciclo de reformas orientadas para a expansão dos sistemas educativos de modo que amplie as possibilidades de um maior número de pessoas ingressarem no sistema. $O$ segundo ciclo está configurado por processos mais complexos e que são denominados de segunda geração, pois estão relacionados com temas como os de gestão de sistema e de qualidade.

\section{UMA PRECISÃO SOBRE O PROCEDIMENTO EMPREGADO}

Os processos de reforma neste novo ciclo não são visíveis imediatamente. Para ter acesso a eles, é necessário configurá-los e estruturá-los. Mais ainda, se se quer fazer um balanço deles, são necessários certos procedimentos metodológicos cujos passos são os seguintes.

O primeiro passo consiste em averiguar quais são os objetivos das reformas, ou seja, determinar o que é que se busca com elas. Esta não é uma pergunta com resposta simples. Se se examinam os planejamentos nacionais de política, pode-se notar, por um lado, que no geral eles não estão formulados em termos de política pública e, por outro lado, que não existe uma maneira uniforme de pleiteá-los. Alguns postulam programas, outros, metas, outros, medidas e outros, princípios gerais. Essa disparidade apresenta dois problemas. Um deles é que não é possível equiparar as políticas nacionais em um nível mais geral. $\bigcirc$ outro é que, salvo no caso em que as formulações expressem metas, os projetos expressam idéias importantes e louváveis, como, por exemplo, "gerar condutas cívicas", mas que na prática são muito difíceis de serem avaliadas. $\bigcirc$ primeiro passo, portanto, 
consiste em identificar, no nível regional, o que se busca com as reformas e quais são seus objetivos.

Um segundo passo é o desenvolvimento de instrumentos que permitam configurar a informação que se irá observar. Isto é importante, pois, como mencionado há pouco, não se trata de observar um ente objetivo. Trata-se, no entanto, de construir os "óculos" que nos permitam observar os processos. Isso se faz pelo desenvolvimento de conceitos e indicadores, instrumentos que nos possibilitem tornar visível o que queremos observar. A este respeito, cabe notar que o "visível" sempre está condicionado pelos conceitos ou "óculos" que utilizamos.

O terceiro passo é o da observação e da medição. Esse é o passo da geração da informação. É importante notar que, em termos de avaliação, a informação e a medição são muito diferentes quando se mede uma vez do que quando se mede duas vezes. Ter dois pontos é muito mais adequado que ter somente um ponto, já que com dois pontos podemos observar a mudança e isso é o que interessa quando se quer avaliar. Em última instância, a avaliação consiste em poder ver a mudança ocorrida.

O quarto passo é o da interpretação. Muitas vezes se pensa que o processo avaliativo termina com a obtenção de um resultado. Sem dúvida, ter um resultado é muito diferente de entender o significado desse resultado. Com freqüência vemos dados, mas poucas vezes contamos com os instrumentos conceituais adequados para interpretá-los. Nesse plano é preciso assinalar que existe um vazio importante quanto a interpretações que proporcionem significado aos resultados que estão aparecendo na região.

E, em último lugar, o quinto passo é o momento da avaliação, que consiste basicamente em formular juízos com base na informação.

\section{OS CONTEXTOS DAS REFORMAS NA AMÉRICA LATINA}

No começo da década e nos anos seguintes, ocorreram certos marcos importantes no contexto dos processos de reformas de educação na América Latina.

O primeiro deles é a Conferência Mundial de Educação para Todos, realizada na Tailândia, em 1990. Essa reunião foi convocada pela Organização das Nações Unidas para a Educação, Ciência e Cultura - Unesco -, pelo Programa das Nações Unidas para o Desenvolvimento - PNUD -, Fundo das Nações Unidas para a Infância - Unicef - e Banco Mundial; o Banco Interamericano de Desenvolvimento - BID - atuou como um dos co-patrocinadores. O propósito fundamen- 
tal da reunião foi o de gerar um contexto político favorável para a educação e orientar as políticas educacionais para fortalecer a educação básica, proporcionar maior atenção aos processos de aprendizagem e buscar satisfazer as necessidades fundamentais de aprendizado.

O instrumento principal para levar isso adiante implicava uma reorientação do crédito internacional. É importante notar que até o momento o crédito dos bancos era para a infra-estrutura. Mais ainda, a década de 80 foi um período de ajuste estrutural, sendo o setor social aquele em que esse ajuste se aplicou com maior rigor; portanto, uma proposta de reorientação dos créditos internacionais era efetivamente importante.

O segundo marco foi o Promedlac IV. Promedlac é a sigla que indica a reunião de Ministros de Educação convocados pela Unesco para analisar o desenvolvimento do Projeto Principal de Educação para a América Latina e o Caribe. Em 1991, em Quito, ocorreu a Quarta Reunião. A Clacso considerou que esta reunião foi o marco mais importante no âmbito da política de educação na década de 90. A declaração emanada desta reunião dizia:

... que as estratégias tradicionais sobre as quais se apoiaram os sistemas educativos da região esgotaram suas possibilidades de conciliar quantidade e qualidade. É por isso que afirmamos... a necessidade de empreender uma nova etapa de desenvolvimento da educação que responda aos desafios da transformação das atividades de produção, da eqüidade social e da democratização política... para fazer face a estas exigências é necessário suscitar uma profunda transformação da gestão tradicional.

Nessa reunião se determinou que a gestão seria o instrumento para passar de uma etapa de desenvolvimento à outra. Avançou-se também na precisão de algumas características que deveria ter esta gestão. $\bigcirc$ novo tipo de gestão deveria facilitar:

I) a abertura do sistema, terminando com sua auto-referência para responder às demandas da sociedade;

2) o estabelecimento de novas alianças, abertura do sistema de participação e tomada de decisões a novos atores e novos aliados;

3) um vasto processo de descentralização, pondo fim ao centralismo histórico;

4) a passagem da ênfase na quantidade para a ênfase na qualidade. 
O terceiro marco foi estabelecido pela $24^{a}$ Reunião da Cepal, que convoca os Ministros da Economia e Finanças. Ela ocorreu em Santiago do Chile, em 1992. Seu propósito era o de analisar a conveniência de voltar a situar a educação e o conhecimento no cerne das estratégias de desenvolvimento. A teoria que sustentava esse objetivo fundamentava-se, por um lado, no fato de que as exigências de crescimento econômico na década de 90 demandavam uma vez mais o investimento em educação. Por outro lado, o crescimento sustentável requeria sociedades integradas e era a educação que poderia contribuir para esse propósito. Dessa maneira, a educação emergia como a única política pública capaz de responder às necessidades de desenvolvimento expressa no crescimento econômico e na integração social. Portanto, dessa reunião surgiu o conceito de que o investimento nacional em educação seria o mecanismo para o desenvolvimento.

O quarto marco foi o Promedlac IV que se realizou em Santiago, em 1993. propósito da reunião era criar, identificar e esboçar ações que permitissem melhorar os níveis de qualidade das aprendizagens. Para tanto, chegou-se à conclusão que no nível macro os instrumentos eram a criação de sistemas nacionais de avaliação e o desenvolvimento de programas de discriminação positiva. No nível micro, a atenção voltou-se para a escola e seus processos.

Em último lugar, o quinto marco, mais técnico que político, foi o Seminário Internacional organizado pela Unesco sobre descentralização e currículo, que ocorreu em Santiago do Chile, em 1993. Nesse seminário discutiu-se a experiência internacional sobre as diferentes modalidades de descentralização curricular e as possibilidades de representar o comum e o diverso no currículo, em particular a redistribuição de competência em matéria curricular no nível macro, com a geração de objetivos e normas gerais e, no nível micro, a introdução de conteúdos locais.

\section{OS OBJETIVOS DA POLÍTICA NO NÍVEL REGIONAL}

Se se analisa o que acontece nas discussões dessas reuniões, que são de caráter político e técnico, pode-se perceber como as autoridades ministeriais e seus assessores colocam em suas agendas um conjunto de reflexões e recomendações que constituem não apenas um contexto, mas também as orientações da política educacional que são assumidas pelo conjunto dos países e, portanto, constituem uma orientação de caráter regional.

Dessas discussões é possível identificar, no plano regional, orientações e objetivos de política, assim como os instrumentos para alcançá-los. Nesse sentido 
pode-se estimar que nos anos 90 foram delineados três objetivos que têm orientado as reformas educacionais na América Latina.

O primeiro objetivo foi o de situar a educação e o conhecimento no centro da estratégia de desenvolvimento por sua contribuição tanto no aspecto econômico quanto no social. Para que isso fosse possível, o instrumento principal foi o de lograr mais recursos financeiros para o setor, a partir do esforço interno e, também, do aumento do crédito internacional mediante endividamento nacional.

O segundo objetivo foi o de iniciar uma nova etapa de desenvolvimento educacional mediante mudanças na gestão. Na prática, isso significa mudar a administração do Estado adotando novo estilo de gestão orientado para a abertura do sistema, o estabelecimento de novas alianças, os processos de descentralização e a ênfase na qualidade e eqüidade.

O terceiro objetivo é melhorar os níveis de qualidade de aprendizado por meio de ações no nível macro e micro. Os instrumentos no nível macro são a instalação de sistemas nacionais de avaliação, o desenvolvimento de programas compensatórios de discriminação positiva e a reforma curricular. No nível micro, a focalização na escola, em particular na gestão escolar, a implantação de graus de autonomia e um currículo adaptado às características das escolas.

\section{O QUE ACONTECEU COM ESTES OBJETIVOS?}

Um assunto importante é verificar o que aconteceu como estes objetivos. Para tanto, é necessário ver o que indicam os instrumentos relacionados com cada objetivo.

\section{Primeiro objetivo: colocar a educação no centro das estratégias de desenvolvimento}

primeiro objetivo procura situar a educação como uma das principais prioridades da política pública. Em geral todos os países incorporaram a educação em seu discurso político, situando-a como um setor estratégico para a inserção de cada país nos processos de globalização, em particular em suas dimensões econômicas. E, em alguns países, como no Chile, a educação foi considerada prioridade.

Se bem que isto ocorra no plano do discurso político, o indicador para saber o nível de apoio que o discurso tem está situado no âmbito financeiro. Em seguida se examina o esforço nacional, visto a partir dos próprios recursos, assim como do endividamento internacional. 
TABELA I

GASTO PÚBLICO EM EDUCAÇÃO

EXPRESSO EM MILHARES DE DÓLARES CONSTANTES DE 1990

\begin{tabular}{|l|r|r|r|r|}
\hline \multicolumn{1}{|c|}{ País } & \multicolumn{1}{c|}{$\mathbf{1 9 8 0}$} & \multicolumn{1}{c|}{$\mathbf{1 9 9 0}$} & \multicolumn{1}{c|}{$\mathbf{1 9 9 4}$} & \multicolumn{1}{c|}{$\mathbf{1 9 9 6}$} \\
\hline Argentina & 4.107 .401 & 1.508 .770 & 7.069 .399 & 6.538 .747 \\
\hline Bolívia & 181.084 & 114.345 & 271.985 & 340.876 \\
\hline Brasil & \multicolumn{1}{c|}{-} & - & - & - \\
\hline Colômbia & 680.417 & 996.217 & 1.663 .367 & 2.184 .764 \\
\hline Costa Rica & 332.556 & 250.133 & 314.422 & 378.936 \\
\hline Chile & 947.920 & 762.590 & 1.133 .602 & 1.410 .964 \\
\hline Cuba & - & - & - & - \\
\hline El Salvador & 212.233 & 105.381 & - & 154.688 \\
\hline Equador & 461.007 & 303.669 & 390.331 & 416.368 \\
\hline Guatemala & 126.289 & 104.263 & 143.390 & - \\
\hline Honduras & 72.590 & 122.679 & 119.610 & 130.628 \\
\hline México & 10.006 .329 & 9.472 .004 & 13.747 .714 & 13.090 .327 \\
\hline Nicarágua & 40.561 & 28.992 & 31.846 & 38.905 \\
\hline Panamá & 202.221 & 247.649 & 305.202 & - \\
\hline Paraguai & 60.797 & 60.487 & 170.264 & 243.445 \\
\hline Peru & 351.490 & - & 507.007 & 428.839 \\
\hline República & - & 8.321 & - & - \\
\hline Dominicana & & & & \\
\hline Uruguai & 186.168 & 247.089 & 253.145 & 342.946 \\
\hline Venezuela & 1.979 .788 & 1.478 .705 & 2.771 .254 & - \\
\hline
\end{tabular}

Fonte: Global Education Data Base e Unesco.

A tabela I mostra o esforço interno de diferentes países nessa matéria. A observação da tabela, expressa em dólares constantes de 1990, mostra que no nível regional o financiamento público caiu entre 1980 e 1990, o período de ajuste estrutural que se efetuou principalmente no setor social. Ao contrário, no período 1990-1996, não só foram recuperados os níveis de 1980, foram ultrapassados na maioria dos casos.

Ao analisar a situação por país, observa-se que a queda do financiamento entre 1980 e 1990 ocorre em II dos 16 países, e em alguns países como Argentina, Chile, El Salvador, Equador e Nicarágua a queda é maior. Em contrapartida, ocorre um ligeiro aumento no Panamá, enquanto Colômbia e Honduras acusam aumentos expressivos. 
Ao ingressar na década dos 90, constata-se que as tendências mudam de sentido. Em 1994, a Argentina, a Colômbia, o Chile, o Paraguai e a Venezuela aumentam extraordinariamente seus investimentos em educação, se comparados a 1990, chegando, na maioria das vezes, a duplicar o investimento. Apenas em Honduras observa-se uma queda.

O gasto em educação cresce em 1996. Nesse ano, perto da metade dos países duplica ou quase duplica o investimento de 1980, especialmente Argentina, Colômbia, Chile, Honduras, Paraguai e Uruguai. Somente El Salvador, Equador e Nicarágua não superam o investimento em educação de 1980. Definitivamente, a Colômbia e o Panamá seguem desde os anos 80 um padrão ascendente (sem baixas em 1990).

O gráfico I mostra o comportamento em forma de $U$ dos gastos públicos em educação entre os anos 1980, 1990, 1994 e 1996. Ele ilustra como o gasto público mais que duplicou entre 1990 e 1996.

\section{GRÁFICO I \\ GASTO PÚBLICO EM EDUCAÇÃO MÉDIA PARA AMÉRICA LATINA}

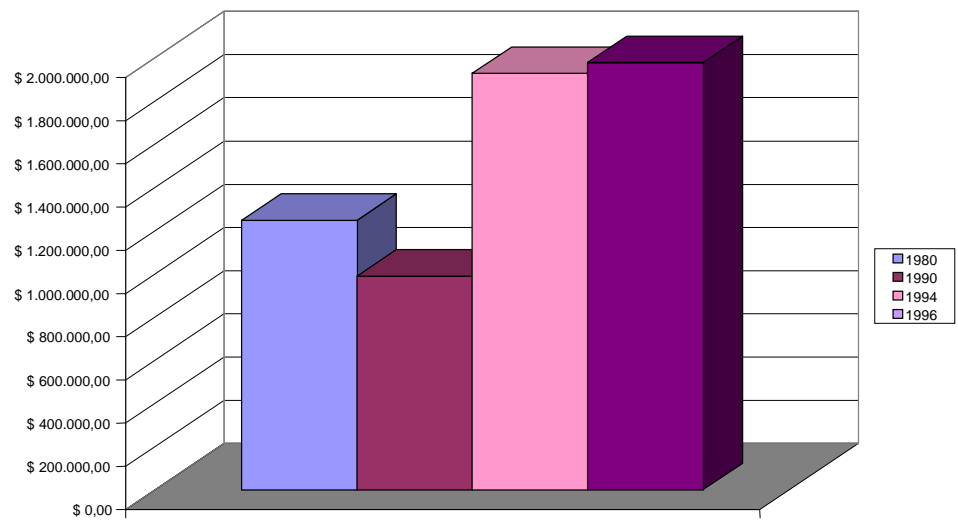

GASTO PÚBLICO EM EDUCAÇÃO EXPRESSO EM MILHARES DE DÓLARES CONSTANTES DE 1990

\begin{tabular}{|l|c|c|c|c|}
\hline \multirow{2}{*}{ Média para América Latina } & 1980 & 1990 & 1994 & 1996 \\
\cline { 2 - 5 } & $1.246 .803,18$ & $988.205,87$ & $1.926 .169,2$ & $1.976 .956,38$ \\
\hline
\end{tabular}

Fonte: Global Education Data Base e Unesco. 
TABELA 2

TOTAL DE GASTO PÚBLICO EM EDUCAÇÃO, EM TERMOS DA PORCENTAGEM DO PNB

\begin{tabular}{|c|c|c|c|c|c|c|}
\hline PAÍS & 1980 & 1990 & ANO & 1994 & 1996 & $\mathrm{ANO}$ \\
\hline Argentina & 2,67 & 1,12 & & 3,77 & 3,50 & \\
\hline Bolívia & 4,42 & 5,39 & & 5,38 & 5,58 & \\
\hline Brasil & 3,60 & 4,55 & 1989 & 1,65 & 5,55 & 1995 \\
\hline Colômbia & 2,38 & 2,61 & & 3,59 & 4,43 & \\
\hline Costa Rica & 7,79 & 4,45 & & 4,54 & 5,33 & \\
\hline Chile & 4,63 & 2,67 & & 2,93 & 3,11 & \\
\hline Cuba & 7,20 & 6,55 & & & & \\
\hline El Salvador & 3,90 & 2,02 & & & 2,19 & 1995 \\
\hline Equador & 5,59 & 3,08 & & 3,41 & 3,47 & \\
\hline Guatemala & $|, 8|$ & 1,39 & & 3,22 & 3,40 & 1995 \\
\hline Honduras & 3,19 & 4,24 & 1989 & 3,48 & 3,02 & 1995 \\
\hline México & 4,73 & 3,73 & & 4,72 & 4,87 & 1995 \\
\hline Nicarágua & 3,38 & 6,56 & 1989 & 3,93 & 3,65 & \\
\hline Panamá & 4,90 & 4,98 & & 4,61 & & \\
\hline Paraguai & $|, 5|$ & 1,12 & & 2,92 & 3,94 & \\
\hline Peru & 3,09 & & & 3,85 & 2,94 & \\
\hline \multicolumn{7}{|l|}{ República Dominicana } \\
\hline Uruguai & 2,29 & 3,08 & & 2,53 & 3,33 & \\
\hline Venezuela & 4,40 & 3,14 & & 5,20 & & \\
\hline médias & 3,97 & 3,57 & & 3,73 & 3,89 & \\
\hline $\begin{array}{l}\text { número de países com } \\
\text { informação }\end{array}$ & 18 & 17 & & 16 & 15 & \\
\hline
\end{tabular}

Fonte: Global Education Data Base e Unesco.

A média regional de investimento público em educação como porcentagem do PNB em 1994 e 1996 supera a porcentagem assinalada em 1990, mas não atinge a de 1980. É interessante notar que os valores desse indicador se elevam num contexto de crescimento da economia na região. $O$ fato sugere que os aumentos das quantidades absolutas destinadas à educação têm sido elevados comparativamente aos padrões do crescimento econômico. Veja-se, a propósito, a tabela 2.

Se se considera o conjunto de países, em 1980 a média de despesas é de 3,97\% do PNB. O país com menor destinação de investimentos é o Paraguai, com ।, $51 \%$ do PNB e os de maiores destinações são Cuba e Costa Rica que superam os 7\% (7,2\% e 7,79\% respectivamente). Em 1990, a média para a região era de $3,57 \%$. Os países que menos destinaram foram Argentina e Paraguai ( I, 12\%). Os que mais destinaram foram Cuba e Nicarágua (6,55\% e 6,56\% respectivamente).

Em 1994, a média de investimento em educação para a América Latina era $3,73 \%$ do PNB. O país que destinou uma porcentagem menor foi o Brasil ( I,65\%) e os que investiram maior porcentagem foram Bolívia e Venezuela. Em 1996, a 
média na região foi de 3,9\% destacando Bolívia e Brasil, com porcentagens maiores aos 5,5\% pontos (5,58\% e 5,55\% respectivamente) e os que realizaram menor destinação foram El Salvador (2,19\%) e Peru (2,94\%).

$\bigcirc$ exposto mostra que a tendência dos países no final da década é destinar uma porcentagem similar do PNB, pois se observa: I) as menores porcentagens de destinação de gastos no período de 1980 a 1990 ( I ,5 I \% e I , I 2\%) são duplicadas no final da década de 90 (3,94\% e 3,50\%). Além disso, destaca que as destinações maiores tendem a baixar, especialmente em 1994. Depois se observa um leve aumento em 1996; 2) a maior parte dos países se aproxima da média regional, quer dizer, destina uma porcentagem em torno de $4 \%$ do PNB, com o que se evidenciam casos extremos, situação que foi característica de períodos anteriores.

$\bigcirc$ esforço empreendido pelos países em termos de créditos contraídos com o Banco Mundial e o BID é mostrado na tabela 3. Nele se avalia que há uma variação nos empréstimos anuais, alcançando o mais alto nível de empréstimos em 1994, com um total para ambos os bancos de um pouco mais de dois bilhões de dólares. Durante os anos 90 e até 1998, o Banco Interamericano de Desenvolvimento havia acumulado um total de US\$3.125.190.000 e o Banco Mundial US\$ 5. I 88.900.000, o que significou um aporte de mais de 8 bilhões de dólares adicionais para a educação. Essas quantias revelam que efetivamente se produziu mudança na política de empréstimos por parte dos dois bancos, tal como fora postulado na reunião de Jomtien, em 1990.

\section{TABELA 3}

\section{APORTES DO BANCO INTERAMERICANO DE DESENVOLVIMENTO} E DO BANCO MUNDIAL(*)

\begin{tabular}{|c|c|c|c|}
\hline ANO & BID & BM & TOTAL \\
\hline 1990 & 14,4 & & $\mathbf{1 4 , 4}$ \\
\hline 1991 & 57,33 & 595,3 & $\mathbf{6 5 2 , 6 3}$ \\
\hline 1992 & 99,1 & 597,1 & $\mathbf{6 9 6 , 2}$ \\
\hline 1993 & 218,9 & 548,7 & $\mathbf{7 6 7 , 6}$ \\
\hline 1994 & 968,75 & 1083,3 & $\mathbf{2 0 5 2 , 0 5}$ \\
\hline 1995 & 106,91 & 747,1 & $\mathbf{8 5 4 , 0 1}$ \\
\hline 1996 & & 493,1 & $\mathbf{4 9 3 , 1}$ \\
\hline 1997 & 704,8 & 61,5 & $\mathbf{7 6 6 , 3}$ \\
\hline 1998 & 955 & 1062,8 & $\mathbf{2 0 1 7 , 8}$ \\
\hline TOTAL & $\mathbf{3 1 2 5 , 1 9}$ & $\mathbf{5 1 8 8 , 9}$ & $\mathbf{8 3 1 4 , 0 9}$ \\
\hline
\end{tabular}

(*) Expresso em milhões de dólares. Fonte: Banco Mundial e BID. 


\section{Segundo objetivo: iniciar nova etapa de desenvolvimento educacional mediante transformação profunda da gestão}

O decisivo nas reformas educacionais na região está centrado na mudança da gestão, mas o processo vai além da mudança de uma técnica de administração. De fato, a mudança aponta, por meio de uma nova estrutura e de outro tipo de gestão, para um âmbito mais político que é o de gerar um novo papel e uma nova administração do Estado no âmbito da educação. Trata-se de, mediante as mudanças na gestão, buscar desenvolver novas formas de regulamentação da atividade educacional. Nesse caso, o Estado decide compartilhar suas atribuições com outros setores da sociedade civil e com outras instâncias administrativas. Para tanto, como já indicado anteriormente, a nova gestão foi caracterizada como aquela que deveria facilitar a abertura do sistema, ser receptiva às demandas da sociedade, favorecer a criação de novas alianças, estar aberta à participação por meio da descentralização e estar orientada para a qualidade e a eqüidade. Isso se traduz principalmente em dois movimentos: I) a abertura a novas alianças e 2) uma nova organização do Estado.

\section{A abertura a novas alianças}

Em termos de abertura do sistema, os países da região ingressaram em um período em que apareceram as mais variadas formas de acordos, tratando de formar coalizões para obter maior estabilidade nos processos educacionais.

Entre as diferentes formas de abertura que se criaram, estão:

- os Congressos Pedagógicos, que são a forma histórica de debate social na educação. Entre eles figuram os da Argentina ( 1987), Bolívia ( 1993) e Chile (1997). Eles se abriram a diferentes forças políticas sociais e sindicais;

- os Acordos Nacionais, em particular o Acordo Nacional para a Modernização da Educação no México ( 1992) e o Acordo Nacional de Educação 2000 no Equador (1993), que constituíram a assinatura de protocolos nacionais mobilizando entidades docentes e intelectuais;

- os Planos Decenais, que apareceram sob diferentes modalidades estratégicas. O Brasil passou de uma primeira etapa, ao estabelecer um Compromisso Nacional de Educação para Todos entre representantes das três esferas da federação (1993), para a elaboração e discussão horizontal - Estado/sociedade civil - e vertical, até mesmo nas escolas, de um Plano Decenal de Educação para Todos ( 1994). Também em uma pers- 
pectiva participativa, a República Dominicana tem elaborado e implementado seu Plano Decenal desde 1990, enquanto, na Venezuela, o Conselho Nacional de Educação desenvolve linhas orientadoras do Plano Decenal mediante planos qüinqüenais ( 1993);

- os Fóruns Públicos dos quais participaram diferentes setores sociais. Eles podiam ser setoriais, como, por exemplo, o Fórum Permanente do Magistério no Brasil (1994), ou gerais como o Fórum Educativo, que é uma associação civil multidisciplinar que opera desde 1992 no Peru.

- as Leis de Educação expressam outro âmbito de acordos, desta vez no quadro legislativo. Assim, foram criadas leis de educação na Argentina (1993), Bolívia (1994), Colômbia (1993 e 1994), Chile (1994/1997), México (1993) e Brasil (1996).

- as Comissões, de tipo acadêmico, como o Comitê de Sábios na Colômbia ( 1994 ) ou de tipo intersetorial, como a Comissão Presidencial para a Modernização da Educação no Chile (1995).

Mediante essas medidas de gestão, as autoridades de Estado convocaram diferentes setores sociais para que participassem na discussão e compromissos com a educação pública.

\section{Uma nova organização do Estado}

Durante a implementação das medidas para a reforma da gestão do sistema educativo, instalaram-se paulatinamente novas pautas de regulamentação da ação educacional. Essas pautas referem-se ao sistema de relações entre atores, determinado por decisões. Nesse sentido é necessário considerar que uma estrutura não é um organograma, mas fundamentalmente um ordenamento das decisões que fazem funcionar uma organização. Esse ordenamento está no mecanismo do exercício do poder numa dada organização. Por isso, a análise do funcionamento de uma organização, que se forja em uma estrutura, é fundamentalmente a análise política na qual se encontra a capacidade de tomar decisões acerca de temas cruciais e, portanto, de regular a ação das pessoas que estão vinculadas, direta ou indiretamente, a tal organização. $\bigcirc$ sistema de decisões estrutura e transforma as relações de poder nas organizações em padrões de relação entre os atores do sistema.

As decisões fundamentais num sistema educacional são aquelas que devem ser tomadas em matéria de política educacional, da avaliação, da determinação de normas, de currículo, do financiamento, de supervisão, da administração das escolas, do contrato com os docentes e do planejamento educacional. 
A seguir, há dois quadros mostrando como se estruturam as decisões cruciais, depois de aplicadas às medidas para mudar a gestão do sistema. No primeiro quadro encontram-se os países federativos e o segundo quadro mostra a situação nos países unitários.

\section{QUADRO I \\ DESCENTRALIZAÇÃO EDUCACIONAL ESTRUTURAS COMPARADAS EM PAÍSES FEDERATIVOS}

\begin{tabular}{|c|c|c|c|}
\hline & $\begin{array}{c}\text { ARGENTINA } \\
(1978-1993)\end{array}$ & $\begin{array}{c}\text { BRASIL } \\
(1971-1988)\end{array}$ & $\frac{\text { MÉXICO }}{\text { (1992) }}$ \\
\hline Sistema de Governo & Federativo & Federativo & Federativo \\
\hline Política Educacional & Nacional & Nacional & Nacional \\
\hline Avaliação & Nacional e provincial & Nacional e estadual & Nacional e estadual \\
\hline Normas & Nacionais & \begin{tabular}{|l|} 
Nacionais \\
Estaduais \\
Municipais \\
\end{tabular} & $\begin{array}{l}\text { Nacionais } \\
\text { Estaduais }\end{array}$ \\
\hline Currículo & $\begin{array}{l}\text { Nacional } \\
\text { (ajuste provincial) }\end{array}$ & $\begin{array}{l}\text { Nacional } \\
\text { Estadual } \\
\text { Municipal }\end{array}$ & $\begin{array}{l}\text { Nacional (com } \\
\text { porcentagem estatal) }\end{array}$ \\
\hline Financiamento & $\begin{array}{l}\text { Co-participação } \\
\text { Federal } \\
\text { Tributos provinciais }\end{array}$ & \begin{tabular}{|l|} 
Federal \\
Estadual \\
Municipal \\
\end{tabular} & \begin{tabular}{|l|} 
Federal \\
Estadual \\
Municipal \\
\end{tabular} \\
\hline Supervisão & Provincial & Compartilhada & Estadual \\
\hline $\begin{array}{l}\text { Administração } \\
\text { de Escolas }\end{array}$ & Provincial & \begin{tabular}{|l|} 
Estadual \\
Municipal \\
\end{tabular} & Estadual \\
\hline Contratação de Docentes & $\begin{array}{l}\text { Provincial } \\
\text { Municipal (Buenos Aires) }\end{array}$ & \begin{tabular}{|l|} 
Estadual \\
Municipal \\
\end{tabular} & Estadual \\
\hline Planejamento & $\begin{array}{l}\text { Nacional, Provincial } \\
\text { Escola (PEI) }\end{array}$ & \begin{tabular}{|l|} 
Federal \\
Estadual \\
Municipal
\end{tabular} & $\begin{array}{l}\text { Nacional } \\
\text { Estadual }\end{array}$ \\
\hline
\end{tabular}

\section{QUADRO 2}

DESCENTRALIZAÇÃO EDUCACIONAL ESTRUTURAS COMPARADAS EM PAÍSES UNITÁRIOS

\begin{tabular}{|c|c|c|c|}
\hline & BOLÍVIA & CHILE & COLÔMBIA \\
\hline & (1994) & (1980) & (1987) \\
\hline Sistema de Governo & Unitário & Unitário & Unitário \\
\hline Política Educacional & Nacional & Nacional & Nacional \\
\hline Avaliação & Nacional & Nacional & Nacional \\
\hline Normas & Nacionais & Nacionais & Nacionais \\
\hline Currículo & $\begin{array}{l}\text { Nacional } \\
\text { (+ Interculturalidade) }\end{array}$ & $\begin{array}{l}\text { Nacional (aberto) } \\
\text { Escolas }\end{array}$ & Descentralizado (?) \\
\hline Financiamento & $\begin{array}{l}\text { Nacional } \\
\text { Municipal e } \\
\text { Comunidade } \\
\end{array}$ & $\begin{array}{l}\text { Nacional, Transferência } \\
\text { Município e } \\
\text { Comunidade } \\
\end{array}$ & Nacional (Fazenda) \\
\hline Supervisão & $\begin{array}{l}\text { Nacional, Distrital, } \\
\text { do Diretor, da } \\
\text { Comunidade } \\
\end{array}$ & $\begin{array}{l}\text { Regional, Provincial } \\
\text { e Municipal }\end{array}$ & $\begin{array}{l}\text { Nacional, Distrital e } \\
\text { Municipal }\end{array}$ \\
\hline $\begin{array}{l}\text { Administração } \\
\text { de Escolas }\end{array}$ & Distrital & $\begin{array}{l}\text { Municipal e } \\
\text { Privada }\end{array}$ & Distrital \\
\hline Contratos Docentes & $\begin{array}{l}\text { Distrital (pagamento } \\
\text { pelo governo central) }\end{array}$ & $\begin{array}{l}\text { Municipal (pagamento } \\
\text { pelo governo central) }\end{array}$ & $\begin{array}{l}\text { Município (pagamento } \\
\text { pelo Distrito) }\end{array}$ \\
\hline Planejamento & Departamental & Municipal (Padem) & Escola (PEI) \\
\hline
\end{tabular}


Desses quadros pode-se observar o papel de nível central e dos demais níveis e formular algumas generalizações a respeito da organização dos sistemas educacionais.

Em primeiro lugar pode-se dizer que, independentemente do sistema de organização do Estado (federativo ou unitário), existe um modelo geral de organização do sistema educacional. Esse modelo corresponde a uma organização de data recente. Na primeira linha é indicado o ano em que se dá início ao processo de descentralização. Talvez convenha notar que há três países nos quais a descentralização se iniciou antes da década de 90. São eles a Argentina, o Brasil e o Chile. As três experiências foram iniciadas em períodos autoritários e sua finalidade era fundamentalmente financeira (reduzir os gastos públicos) e política (dividir o movimento sindical). Nisso esses processos foram radicalmente diferentes dos que ocorreram nos anos 90, cuja política foi orientada a finalidades tais como aumentar a participação dos distintos setores sociais e consolidar a democracia. Pode-se avaliar que efetivamente na região se produziu uma mudança na gestão. A estrutura resultante é diferente da tradicional e em sua reformulação todos os países considerados assumem uma nova estrutura que é muito similar em seus traços essenciais. Essa nova estrutura é homogênea mediante os países e, portanto, corresponde à constituição de um modelo regional comum.

Uma segunda observação é que nesse modelo pode-se notar que foi criado um padrão de descentralização cujos processos não são independentes dos processos de centralização. Se se consideram os quadros a partir das linhas, em todos os países, independentemente do fato de serem federativos ou unitários, as decisões de política educaciona/são tomadas no âmbito central. Do mesmo modo, as decisões de avaliação são tomadas nesse âmbito, ainda que costumem ser complementadas por decisões no nível provincial ou estadual. As decisões quanto às normas são também tomadas no nível central e em alguns casos são complementadas no nível provincial ou estadual. Quanto ao currículo, que é outro âmbito estratégico, ele é definido no nível central quanto a seus marcos gerais, mas com adaptações em outros níveis descentralizados. Por seu lado, o financiamento é invariavelmente um recurso de origem nacional. Não obstante, nos países ocorrem diferentes modalidades de aportes nos níveis provincial, estadual, municipais e comunitários.

As outras decisões, que têm a ver com a operação do processo pedagógico, são tomadas nas esferas administrativas menores. Assim, supervisão se situa predominantemente nos níveis provinciais, estaduais e municipais. A administração das escolas e os contratos com os docentes situam-se também na esfera das pro- 
víncias, estados e municípios. Finalmente, as atividades de planejamento se distribuem entre os diferentes níveis educacionais de governo.

A mudança na estrutura e conteúdo das decisões, assim como os novos compromissos de gestão dos sistemas educacionais nos anos 90 dão forma a um modelo de estrutura que se esquematiza no quadro 3. Nessa nova configuração consideram-se vários aspectos: um deles mostra que no sistema de decisões se distinguem, por um lado, aquelas de caráter estratégico-político e, por outro, aquelas de caráter operacional-profissional.

\section{QUADRO 3}

\section{MODELO DE ESTRUTURA EDUCACIONAL}

\begin{tabular}{|c|l|l|l|}
\hline \multirow{2}{*}{ Homogêneo } & \multicolumn{1}{|c|}{ Central Estratégico } & \multicolumn{1}{|c|}{ Compartilhado } & \multicolumn{1}{c|}{ Local Operativo } \\
\cline { 2 - 4 } & $\begin{array}{l}\text { Política Educacional } \\
\text { Avaliação } \\
\text { Normas }\end{array}$ & & \\
\hline Misto & & $\begin{array}{l}\text { Currículo } \\
\text { Financiamento } \\
\text { Planejamento }\end{array}$ & \\
\hline Heterogêneo & & & $\begin{array}{l}\text { Supervisão } \\
\text { Administração Escolas } \\
\text { Contratos docentes }\end{array}$ \\
\hline
\end{tabular}

Outro aspecto a notar é que o modelo é homogêneo e também heterogêneo. A situação é a mesma em todos os países, ou seja, homogênea em relação às decisões que são tomadas pelo centro. A situação é a mesma quanto às decisões referentes a currículo, financiamento e planejamento, as quais são compartilhadas com outros níveis. Quanto às decisões de caráter operacionais, a situação também é idêntica. Ainda que em todos os países as decisões operacionais sejam tomadas em esferas administrativas menores, é nesse nível em que se aprecia a diversidade quanto às formas concretas em que se dão as soluções organizativas.

\section{Terceiro objetivo: melhorar os níveis de qualidade da aprendizagem}

Esse terceiro objetivo orienta-se para a consolidação das novas estruturas mediante o estabelecimento de instrumentos e ações no nível macro e micro. Ao mesmo tempo, tenta modificar os processos e conteúdos da aprendizagem. Os instrumentos no nível macro são a implementação de sistemas nacionais de avaliação, o desenvolvimento de programas compensatórios de discriminação positiva e a reforma curricular. No nível micro, a focalização na escola e em particular na gestão escolar, a implantação de graus de autonomia e um currículo adaptado às características das escolas. 
São dois então os aspectos que aparecem como centrais na nova estrutura de nível macro: a avaliação de desempenho e a capacidade de intervir nas escolas mediante programas de discriminação positiva.

As novas estruturas que se depreendem dos quadros I e 2 mostram que o Estado central guardou para si um conjunto de decisões estratégicas.

No caso da avaliação de desempenho, no período em estudo, foram criados sistemas de medição e de avaliação do rendimento escolar, não só nos países constantes do quadro mas também em todos os países da região, com exceção de Cuba. Esta se converteu em uma peça-chave da nova gestão e do novo papel do Estado, que entrega diferentes graus de liberdade a instâncias administrativas menores, em troca de uma nova capacidade de avaliar. Essa instância tem sido tão generalizada que, em 1995, foi criado o Laboratório Latino Americano de Avaliação da Qualidade da Educação, coordenado pela Unesco. A entidade de caráter regional publicou recentemente o Primeiro Estudo Comparativo Internacional (Unesco, 1998). O estudo faz uma comparação do rendimento acadêmico de 14 países e o mais notável é que foi realizado com uma mesma prova baseada nos conteúdos comuns que se empregam em todos os sistemas educacionais da região. Em outras palavras, nos sistemas educacionais da região, exceto as particularidades nacionais, existe um currículo comum regional.

O segundo tipo de decisões refere-se à capacidade de intervir nas escolas mediante programas de discriminação positiva. Essa dimensão é interessante, uma vez que, paralelamente às políticas de descentralização, o Estado central se reservou a capacidade de gerar programas de intervenção nas escolas. Essa capacidade de intervenção encontra sua justificativa na necessidade de o Estado central velar pela eqüidade no sistema.

\section{QUADRO 4 PROGRAMAS DE DISCRIMINAÇÃO POSITIVA}

\begin{tabular}{|l|l|}
\hline Argentina & Plano Social, Nova Escola \\
\hline Bolívia & Interculturalidade e Participação Cidadã (Pace) \\
\hline Brasil & $\begin{array}{l}\text { Classes de Aceleração de Aprendizagem, Fundo de Manutenção e } \\
\text { Desenvolvimento do Ensino Fundamental }\end{array}$ \\
\hline Chile & P900, Mece rural \\
\hline Colômbia & Escola Nova \\
\hline El Salvador & Educo (autogestão comunitária) \\
\hline Guatemala & Pronade (autogestão comunitária) \\
\hline México & Programa de Compensação do Atraso Escolar na Educação Básica (Pareb) \\
\hline Paraguai & Escola ativa Mita Iru (multigrau) \\
\hline Venezuela & Escola rural indígena e de fronteiras \\
\hline
\end{tabular}


Este quadro mostra que nos governos foi abandonado o critério de homogeneidade e desenvolvida uma série de programas e projetos orientados para compensar ou remediar as deficiências percebidas no desempenho das escolas. De fato, em alguns países, como no Chile, os sistemas de avaliação trouxeram dados necessários para poder focalizar medidas de reforço educacional para meIhorar o rendimento nas escolas deficitárias. Muitos desses programas, como é o caso do Plano Social da Nova Escola na Argentina, as classes de aceleração no Brasil, o P900 no Chile, Educo em El Salvador, Escola Nova na Colômbia ou o Programa de Compensação do Atraso Escolar no México, chamaram a atenção internacional como programas vitoriosos e que serviram de inspiração para outros sistemas educacionais.

Se notarmos seu papel na nova gestão do sistema educacional, os traços comuns que existem no desenho e operação de tais programas, uma vez mais poderemos perceber que existem influências mútuas operando na região, a ponto de caracterizar os enfoques como enfoque regional apesar de existirem naturais matizes entre os países.

Quando os países completam seus processos de reforma da gestão do sistema, a atenção começa a ser focalizada na reforma do currículo. Ainda quando essa ocorre em diferentes momentos a partir de 1995, os padrões que guiam as reformas dos países são, uma vez mais, similares. A reforma curricular se concretiza em quatro aspectos: desenvolvimento de quadros curriculares comuns; a adaptação desse quadro comum no nível regional e local; a passagem das disciplinas para as áreas temáticas e a visão transversal, bem como a passagem dos objetivos cognitivos para objetivos de competência.

No nível micro, o fato mais notável é a focalização na escola. De algum modo, os processos de descentralização estão tocando a escola e a perspectiva das medidas de política tende a centrar-se nesse nível. Nesse domínio, a atenção tem sido centrada em particular na gestão escolar. Ali foram introduzidas novas orientações que tendem a gerar diferentes graus de autonomia. Os níveis de autonomia variam consideravelmente de país para país, mas o tema da autonomia está estabelecido. O outro tema que diz respeito ao nível micro é o da pedagogia; nele se busca o desenvolvimento de estratégias pedagógicas adaptadas às características da cultura, incluindo tanto as práticas como alguns dos conteúdos curriculares.

\section{CONCLUSÕES}

A análise deste breve texto foi orientada para destacar três aspectos. 
O primeiro é que dentro do contexto da globalização, é possível perceber a emergência de um nível regional no plano da cultura e que esse se expressa com clareza na instituição educacional. As políticas regionais transcendem o nível da política educacional nacional mas também a influenciam, pois se refletem nela. Dito de outra maneira, as políticas nacionais estão enquadradas em sistemas de idéias que constituem o contexto maior que as estrutura e lhes dá conteúdos, que são os conteúdos das reformas. Esse nível está portanto dotado de historicidade. Seu desenvolvimento ocorre principalmente no intercâmbio e no diálogo entre os atores políticos, seja em reuniões político-técnicas no plano internacional, tanto no nível presidencial e ministerial como em níveis mais técnicos. Também ocorre em intercâmbios, ou seja, por meio de estágios, ou por meio da cooperação técnica internacional multilateral e bilateral, na maioria das vezes com caráter horizontal. Finalmente, também ocorre em contextos não formais por meio de revistas e conferências. Essa operação tem frutificado pela existência de um substrato cultural comum, cujos códigos têm sido veiculados mediante o sistema educacional.

Uma vez que a existência desse nível regional se torna inteligível, o segundo aspecto é a identificação dos conteúdos macros desses processos regionais, independentemente das variações que ocorrem no nível nacional e local. A estruturação desses conteúdos se expressa nas recomendações e declarações que emergem de pessoas que ocupam o cenário do poder, como os presidentes e, particularmente, os ministros e seus assessores. Assinalou-se que fundamentalmente esses conteúdos se expressam em objetivos que são: em primeiro lugar, o reposicionamento da educação no quadro das estratégias de desenvolvimento como uma política pública prioritária; em segundo lugar, a geração de nova etapa de desenvolvimento educacional impulsionada por uma nova gestão apoiada na reestruturação do papel do Estado; em terceiro lugar, a melhoria da qualidade e a eqüidade na educação.

O terceiro aspecto consistiu no aporte de informações que permitam fazer um balanço desses objetivos depois de uma década de reforma educacional na região.

Em relação ao primeiro objetivo: "voltar a situar a educação no centro das estratégias do desenvolvimento, apoiada em mais recursos financeiros", pode-se avaliar que a maioria dos países colocou no discurso político a educação como prioridade política; também a maioria dos países tem aumentado, em termos absolutos e relativos, os recursos para a educação. Uns o fizeram em maior medida que outros e alguns têm diminuído os recursos. Por seu lado, o Banco Mundial e o 
Banco Interamericano de Desenvolvimento reorientaram sua política de crédito para a educação.

Quanto ao segundo objetivo: "gerar nova etapa de desenvolvimento educacional, mediante um novo estilo de gestão", pode-se considerar que, em relação:

I. à abertura do sistema e ao estabelecimento de novas alianças, no nível macro, a gestão se abre no início da década de 90, como evidencia a variedade de estratégias de acordos. Não obstante, o impulso para a geração de novas alianças iniciado no começo da década, com o desgaste e a dificuldade da gestão, transforma-se em um terreno nebuloso até o fim da década. No nível micro, a abertura do sistema tem sido menos evidente. Isso se deve principalmente às dificuldades relacionadas com a cultura tradicional, à falta de preparo dos recursos humanos e às limitações nas atribuições dos diretores dos estabelecimentos escolares

2. aos processos de descentralização, todos os países descentralizaram-se. As exceções são o Peru e o Equador, que anunciaram tais processos mas não os realizaram. A descentralização tem sido um processo de redistribuição de poder mediante a entrega de poderes às instâncias administrativamente inferiores. Não obstante, ao mesmo tempo, o centro ficou com as atribuições estratégicas e foram sendo geradas novas funções nesse nível, de sorte que a descentralização vem sendo aparelhada com processos de centralização. Por isso, o objetivo na prática se modificou com a geração de redes mediante o estabelecimento de sistemas de informação mais adequados. Do ponto de vista do poder, este foi distribuído especialmente nos países federativos e, globalmente, gerouse mais poder no setor.

Quanto ao terceiro objetivo: "melhorar os níveis de qualidade das aprendizagens mediante ações no nível macro e micro", é possível notar que no plano macro todos os países desenvolveram sistemas de avaliação, todos delinearam e estão concluindo programas de discriminação positiva. Em contrapartida, os países que iniciaram uma reforma educacional apresentam marcos normativos gerais orientados para a cidadania e a transversalidade. No plano micro considera-se que se apresentam diversos graus de autonomia da escola; apesar disso, tem sido difícil viabilizar a abertura do currículo.

Por último, algumas considerações para encerrar. Em primeiro lugar, podemos considerar que ao final do decênio, no segundo ciclo de reformas educacio- 
nais, existe uma grande homogeneidade nas tendências macro. As reformas são muito parecidas em todos os países, mas à medida que vão se aprofundando os processos de descentralização, no nível local começa-se a notar grande diversidade e inovações interessantes. As reformas têm fomentado, por um lado, uma homogeneidade que reflete os sistemas de idéias prevalecentes e, por outro lado, têm fomentado a heterogeneidade e a diversidade no nível micro.

Em segundo lugar, a educação é percebida como um instrumento de acesso à modernidade e à globalização. Mas esses conceitos orientadores não estão isentos de problemas teóricos - pelo que se torna urgente uma nova definição das finalidades da educação - e práticos, principalmente aqueles ligados à exclusão social.

Em terceiro lugar, passou-se de uma visão focalizada nos insumos, quer dizer, de uma política desenhada em torno de recursos para uma política focalizada nos resultados. É por isso que a avaliação tornou-se tão crucial. Há dez anos o resultado da ação educacional era invisível. Agora é pedra angular sobre a qual irão se desenhar as políticas. Nesse sentido, a configuração dos instrumentos de avaliação é um dos temas mais sensíveis, mais importantes e menos conhecidos nos processos de reforma'.

Em quarto lugar, nota-se que o discurso da reforma tem sido basicamente o da gestão, deixando o tema dos fins relegado a um segundo plano. Ainda que a preocupação tenha estado na gestão e que se tenham desenvolvido os sistemas de informação para a gestão, estes ainda não estão suficientemente aprimorados em seu delineamento, de modo que assegure que as decisões tomadas sejam as mais adequadas.

Em quinto lugar, a implementação das próprias reformas tem padecido de muitas dificuldades. Elas estão sendo executadas, mas o processo tem provocado muitas resistências e sofrimento que talvez pudessem ter sido evitados. A reforma curricular é complexa e altera a formação tradicional dos professores, a que se somam a dificuldade de requalificação e a dificuldade de mudança cultural.

Por sua orientação para a gestão, a reforma pode ser caracterizada como um esforço importante para criar as condições para melhorar os níveis de qualida-

I É sensível por dois motivos: a) porque consagra a idéia do resultado em uma atividade que é multidimensional, na qual muitos questionam a possibilidade de se determinar um resultado; b) porque colocar uma prova ao final de um processo orienta o conjunto do processo para os conteúdos da prova. 
de. Não obstante, é difícil saber se efetivamente terão melhorado esses níveis. Os sistemas de avaliação da qualidade da educação não contam com as séries históricas equalizadas que permitem avaliar as mudanças de rendimento ao longo dos anos. As mudanças ocorridas são importantes e serviram para mostrar a complexidade com que ocorrem as mudanças da educação. Depois de dez anos, as mudanças também foram assimiladas pela população e parecem naturais. Por isso, é interessante destacar o dinamismo do setor e recordar que tem sido o setor da educação que tem operado como ponta-de-lança da reforma do Estado.

\section{REFERÊNCIAS BIBLIOGRÁFICAS}

UNESCO. Primeiro estudo comparativo internacional. Santiago do Chile: Laboratório Latino Americano de Avaliação de Qualidade da Educação, 1998. 